Radiative deactivation of lowest singlet and triplet excited states of water-soluble porphyrins

V. N. Knyukshto, ${ }^{a}$ A. S. Starukhin, ${ }^{a}$ M. M. Kruk, ${ }^{b}$ and A. V. Gorskii ${ }^{\mathrm{c}}$

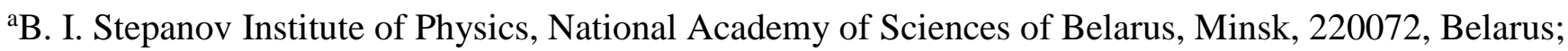

belarusian State Technological University, 13a Sverdlov Str., Minsk, 220006, Belarus;

'Institute of Physical Chemistry, Polish Academy of Sciences, Warsaw, 02-244, Poland;

Journal of Applied Spectroscopy, Vol. 84, No. 6, January, 2018

DOI 10.1007/s10812-018-0571-2

This project has received funding from the European Union's Horizon 2020 research and innovation programme under the Marie Skłodowska-Curie grant agreement No. 645628

Project Number: 645628

Project Acronym: METCOPH

Project title: Metallocomplexes of macrocyclic compounds for photonic devices 


\title{
RADIATIVE DEACTIVATION OF LOWEST SINGLET AND TRIPLET EXCITED STATES OF WATER-SOLUBLE PORPHYRINS
}

V. N. Knyukshto, ${ }^{a}$ A. S. Starukhin, ${ }^{a}$ M. M. Kruk, ${ }^{b}$ and A. V. Gorskii ${ }^{c}$

${ }^{a}$ B. I. Stepanov Institute of Physics, National Academy of Sciences of Belarus, Minsk, 220072, Belarus;

belarusian State Technological University, 13a Sverdlov Str., Minsk, 220006, Belarus;

'Institute of Physical Chemistry, Polish Academy of Sciences, Warsaw, 02-244, Poland;

\begin{abstract}
Radiative deactivation of lowest excited triplet and singlet states for series offree bases and $\mathrm{Zn}^{2+}$ complexes of water-soluble 5,10,15,20-tetrakis-(4-sulfonatophenyl)porphyrin ( $\left.\mathrm{H}_{2} \mathrm{T4SPP}\right)$; 5,10,15,20-tetrakis-(4-N-alkylpyridyl) porphyrin (H2T4AlkPyP); and 5,10,15,20-tetrakis-(3-Nalkylpyridyl)porphyrin ( $\left.\mathrm{H}_{2} \mathrm{T3AlkPyP}\right)$ was studied in solutions at 77 and $293 \mathrm{~K}$. The fluorescence and phosphorescence quantum yields were found to have small but detectable differences for derivatives of the same porphyrin ligand with different counterions for the ionized aryl substituents. It was shown that these differences were due to spin-orbit coupling effects and variation of the electron donor/acceptor properties of the peripheral substituents that changed the electronic energy levels in the porphyrin-counterion system.
\end{abstract}

Keywords: water-soluble porphyrin, phosphorescence, fluorescence. 
Introduction. Water-soluble porphyrins occupy a special place among numerous tetrapyrrole derivatives because they have great potential for practical applications in medicine, biology, and industry as drugs, catalysts, and reaction inhibitors and sensitizers [1,2]. Water-soluble porphyrins have ionizable peripheral substituents, in contrast with their hydrophobic analogs, and can be salts of acids or bases [24]. The ionizable peripheral substituents carry either a negative $\left(\mathrm{H}_{2} \mathrm{~T} 4 \mathrm{SPP}\right)$ or positive charge ( $\mathrm{H}_{2}$ T4MPYP) that is responsible for the hydrophilic properties of the porphyrin as a whole although the tetrapyrrole macrocycle itself is hydrophobic. Therefore, solutions of the tetrapyrroles also contain counterions (sometimes protons) that can either dissociate or form ion pairs with the ionized tetrapyrrole macrocycle substituents to establish dynamic equilibrium depending on the physicochemical microenvironment $[3,4]$. Intermolecular interactions of tetrapyrroles with their counterions produce noticeable changes in the electronic absorption and vibrational spectra and affect the rate constants of intramolecular transitions and intermolecular interactions [3-6]. The spectroscopic manifestations of intermolecular interactions of ionized peripheral groups with ions (including the counterions themselves) was proposed to be called halochromism of water-soluble tetrapyrroles [3, 4]. Deactivation of electronic excitation energy in water-soluble tetrapyrroles was studied several times [7-13]. Attention was paid mainly to the fluorescence properties. As a rule, studies of triplet states were limited to measurements of the quantum yield of photosensitized singlet oxygen formation $[9,11]$. Population and deactivation of triplet states of water-soluble tetrapyrroles and the role of structural features (peripheral ionizable substituents and their molecular structure) were beyond the scope of the work.

The principal information source for the spectroscopic properties of the lowest triplet state is still the work of Kalyanasundaram et al. that was published over 30 years ago [7, 8]. The effect of the structural features of water-soluble tetrapyrroles on quenching of their triplet states by $\mathrm{O}_{2}$ was studied [12]. Therefore, it seemed timely to analyze the whole database of spectroscopic properties of watersoluble tetrapyrrole triplet states taking into account their structural features. 
The present work measured spectra and phosphorescence quantum yields and lifetimes of free bases of differently charged water-soluble porphyrins, i.e., anionic 5,10,15,20-tetrakis-(4sulfonatophenyl)porphyrin ( $\left.\mathrm{H}_{2} \mathrm{~T} 4 \mathrm{SPP}\right)$ and two cationic

\section{5,10,15,20-tetrakis-(4- $\mathrm{N}$-alkylpyridyl)porphyrin $\quad\left(\mathrm{H}_{2} \mathrm{~T} 4 \mathrm{AlkPyP}\right) \quad$ and $\quad 5,10,15,20$-tetrakis-(3- $N$ -} alkylpyridyl)porphyrin

$\left(\mathrm{H}_{2} \mathrm{~T} 3 \mathrm{AlkPyP}\right)$ and their $\mathrm{Zn}^{2+}$-complexes. In addition, the relationship between the nature of the porphyrin counterion and

the measured spectroscopic properties was analyzed.

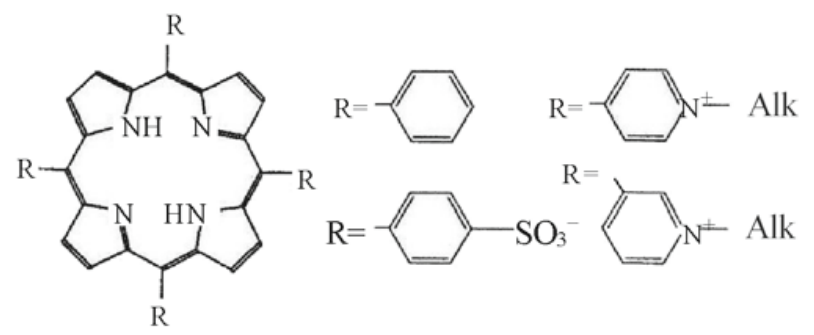

Fig. 1. Molecular structures of studied compounds; all R substituents in macrocycle meso- positions are identical: $\mathrm{R}=\mathrm{H}_{2} \mathrm{TPP} ; \mathrm{H}_{2} \mathrm{~T} 4 \mathrm{SPP}$; $\mathrm{H}_{2}$ T4AlkPyP; and $\mathrm{H}_{2}$ T3AlkPyP; structures are shown for the free bases; counterions are not shown.

Experimental. Halides and tosylates of cationic porphyrins $\mathrm{H}_{2} \mathrm{~T} 4 \mathrm{AlkPyP}$ and $\mathrm{H}_{2} \mathrm{~T} 3 \mathrm{AlkPyP}$ (Fig. 1) were synthesized by the literature methods [13]. The sodium salt of anionic $\mathrm{H}_{2} \mathrm{~T} 4 \mathrm{SPP}$ was used [14]. The standard compound for the spectral and luminescence parameters was 5,10,15,20tetraphenylporphyrin ( $\left.\mathrm{H}_{2} \mathrm{TPP}\right)$. The substituents bound to the quaternized pyridyl $\mathrm{N}$ atom were methyl 
$\left(\mathrm{M}, \mathrm{CH}_{3}\right), 2$ '-hydroxyethyl $\left(\mathrm{OE},-\mathrm{CH}_{2}-\mathrm{CH}_{2}-\mathrm{OH}\right)$, and allyl $\left(\mathrm{Al},-\mathrm{CH}_{2}-\mathrm{CH}=\mathrm{CH}_{2}\right)$. The solvent was distilled and dried EtOH that formed a glass at $77 \mathrm{~K}$. The water-soluble porphyrins were highly aggregated in aqueous solutions at $77 \mathrm{~K}$. Therefore, porphyrin concentrations of $(1-2) \cdot 10^{-5} \mathrm{M}$ were determined spectrophotometrically using known extinction coefficients [7, 8, 15]. Electronic absorption spectra were recorded on a CARY 500 Scan spectrophotometer (Varian). Experiments at $293 \pm 2 \mathrm{~K}$ used standard quartz cuvettes $(1 \times 1 \mathrm{~cm})$. Measurements at $77 \mathrm{~K}$ were taken by placing samples into an optical quartz Dewar flask. Weak fluorescence was isolated using a dual-disk phosphoroscope. The lifetime of the lowest triplet $T_{1}$-state was determined from the phosphorescence decay kinetics. The excitation source was an SSh-20 pulsed Xe lamp (2- $\mu$ s pulse). Phosphorescence decay was recorded at the phosphorescence maxima of the studied compounds and stored in a C9-8 oscilloscope. Fluorescence lifetime was measured on a PRA-3000 pulsed fluorometer operating in photon-counting mode. Fluorescence and phosphorescence spectra were measured on a high-sensitivity spectrometer that was described in detail before [16].

Results and Discussion. Solutions of the water-soluble tetrapyrroles in $\mathrm{EtOH}$ were used to study the role of anion-cation interactions between the ionized peripheral substituents and the counterions in producing the spectroscopic properties. EtOH was chosen to model a weakly dissociating experimental medium instead of the usually used $n$-octanol for two reasons. First, it was shown earlier by us that $\mathrm{H}_{2} \mathrm{~T} 4 \mathrm{SPP}$ and $\mathrm{H}_{2} \mathrm{~T} 4 \mathrm{MPyP}$ in aqueous $\mathrm{EtOH}$ solutions with $\sim 50 \mathrm{vol}$ \% EtOH formed undissociated species, i.e., the counterions were bound to the peripheral substituents. Second, EtOH forms a glass upon freezing, in contrast with $n$-octanol. Therefore, it produces stable transparent solid solutions, which are necessary for actinometry of absorbed light to determine emission quantum yields at $77 \mathrm{~K}$.

Figure 2 shows fluorescence excitation, fluorescence, and phosphorescence spectra of the free base tetraiodides and the Zn-complex of 5,10,15,20-tetrakis-(4- $N$-methylpyridyl)porphyrin ( $\left.\mathrm{H}_{2} \mathrm{~T} 4 \mathrm{MPyP}\right)$ 
in EtOH at 77 and $293 \mathrm{~K}$. Table 1 presents the spectroscopic properties of the free bases and $\mathrm{Zn}$-complexes of all studied compounds at $77 \mathrm{~K}$ that were calculated from the spectra. Before analyzing the obtained experimental results, it should be noted that the studied compounds included one anionic porphyrin and several cationic derivatives. However, the sign and size of the molecular charge ( $-4 e$ for $\mathrm{H}_{2} \mathrm{~T} 4 \mathrm{SPP}$ or $+4 e$ for $\mathrm{H}_{2} \mathrm{~T} 4 \mathrm{MPyP}$ ) had little effect on the measured spectroscopic and photophysical properties (Table 1) because the charge was localized on the substituents and did not affect the chromophore, i.e., the conjugated $\pi$-system of the tetrapyrrole macrocycle. Furthermore, the charge was compensated by the bound counterions in the undissociated species so that the molecule as a whole was neutral.

Counterions are situated in close proximity to the tetrapyrrole macrocycle conjugated $\pi$-system if the undissociated porphyrin species forms. Manifestation of an internal heavy-atom effect in the photophysical properties of the porphyrins analogous to that of hydrophobic halogenated tetraarylsubstituted tetrapyrroles [17] should be expected if the spin-orbit coupling constant of the counterions is large (e.g., if they are halides for cationic porphyrins). Fluorescence quantum yields $\Phi_{\mathrm{fl}}$ of $\mathrm{H}_{2} \mathrm{~T} 4 \mathrm{MPyP}$ derivatives with various counterions were measured in EtOH solutions at $293 \mathrm{~K}$. The quantity $\Phi_{\mathrm{fl}}$ did infact decrease $(0.056>0.052>0.046>0.038)$ in the order of counterions $\mathrm{NO}^{-}>\mathrm{Tos}^{-}$ $>\mathrm{Cl}^{-}>\Gamma^{-}$. The spin-orbit couplingconstant $\xi$ of the counterions increased in this order by practically an order of magnitude, from 540 to $5069 \mathrm{~cm}^{-1}$. Such a clear correspondence was not observed for the fluorescence quantum yield $\Phi_{f l}$ at $77 \mathrm{~K}$ (Table 1). 
TABLE 1. Spectral and Luminescence Characteristics of Free Bases and Zn-Complexes of Water-Soluble Porphyrins in EtOH at $77 \mathrm{~K}$

\begin{tabular}{|c|c|c|c|c|c|c|}
\hline & & & $\Delta E\left(S_{1-}\right.$ & & & \\
\hline \multicolumn{7}{|c|}{ Free } \\
\hline $\mathrm{H}_{2} \mathrm{TPP}$ & 645 & 859 & 386 & 12.0 & 0.67 & 5.6 \\
\hline $\mathrm{H} 2 \mathrm{~T} 4 \mathrm{SPP} / \mathrm{Na}^{+}$ & 641 & 850 & 384 & 13.5 & 1.6 & - \\
\hline $\mathrm{H}) \mathrm{T} 4 \mathrm{MPyP}^{-} \mathrm{I}^{-}$ & 641 & 826 & 349 & 8.7 & 4.3 & - \\
\hline $\mathrm{H}$ วT4MPyP/Tos ${ }^{-}$ & 641 & 826 & 349 & 7.4 & 2.6 & 9.9 \\
\hline $\mathrm{H} 2 \mathrm{~T} 4 \mathrm{MPyP}^{-\mathrm{NO}^{-}}$ & 640 & 825 & 349 & 11.5 & 3.1 & 11.0 \\
\hline $\mathrm{H}$ )T4MPyP/Cl ${ }^{-}$ & 641 & 824 & 346 & 7.9 & 2.3 & 9.4 \\
\hline $\mathrm{H}_{2} \mathrm{~T} 4 \mathrm{OEPyP} / \mathrm{Tos}^{-}$ & 641 & 826 & 349 & 10.0 & 3.7 & 11.8 \\
\hline H2T3OEPyP/Tos & 637 & 822 & 353 & 5.3 & 2.5 & 11.1 \\
\hline \multicolumn{7}{|l|}{ H) IJUER YP/IOS } \\
\hline ZnTPP & 602 & 782 & 382 & 3.3 & 3.6 & 25.5 \\
\hline $\mathrm{ZnT} 4 \mathrm{SPP} / \mathrm{Na}^{+}$ & 596 & 774 & 386 & 5.6 & 6.5 & 26.0 \\
\hline${\mathrm{ZnTMPyP} / \mathrm{I}^{-}}^{-}$ & 607 & 751 & 310 & 3.2 & 13.0 & 23.4 \\
\hline $\mathrm{ZnT} \mathrm{OEPyP} / \mathrm{Tos}^{-}$ & 608 & 752 & 315 & 4.7 & 16.0 & 32.0 \\
\hline $\mathrm{ZnT} \mathrm{OEPyP} / \mathrm{Tos}^{-}$ & 597 & 745 & 333 & 1.5 & 13.0 & 31.0 \\
\hline ZnT4AlPyP/Tos ${ }^{-}$ & 611 & 753 & 309 & 3.3 & 13.0 & 32.5 \\
\hline
\end{tabular}

The phosphorescence quantum yield was greatest for the derivative with an $\mathrm{I}^{-}$counterion, $\Phi_{\text {phos }}=4.3 \cdot 10^{-4}$. However, the values for the studied series of compounds were not fully correlated with the spin-orbit coupling constant. The phosphorescence lifetime $\Phi_{\text {phos }}$ at $77 \mathrm{~K}$ was inversely proportional to the $T_{1}-S_{0}$ intersystem-crossing rate constant. If this quantity was mainly determined by a heavy-atom effect, then the phosphorescence lifetime should decrease with increasing spin-orbit coupling constant $\xi$ of the counterions. However, a distinct dependence of the data for the porphyrin free bases was not observed in Table 1. The phosphorescence lifetimes of only two derivatives could be compared for the Zn-complexes. Therefore, only the trend can be discussed.

Obviously, two factors could be responsible for the lack of distinct correlations of the aforementioned quantities and the spin-orbit coupling constant. First, the molecular structure of the 
porphyrin-counterion system could change in the frozen solid solution. Second, effects due to redistribution of electron density between the tetrapyrrole macrocycle and the substituents could be superimposed on the relatively small observed heavy-atom effects. These effects could also be temperature dependent because the dihedral angle between the macrocycle mean plane and the planes of the aryl fragments could change considerably on going from a liquid solution at $293 \mathrm{~K}$ to a solid solution at $77 \mathrm{~K}$. In fact, the tetrapyrrole macrocycle $\pi$-system is not directly influenced by interaction with counterions of peripheral groups in the phenyl para- and meta-positions. Phenyl and pyridyl fragments are known to be electron-density donors so that symmetric addition of them to the porphyrin macrocycle meso-positions increases the energy of the $a_{2} u$-orbital, which has non-zero electron density on the macrocycle $\mathrm{C}_{\mathrm{m}}$ atoms $[18,19]$. It is noteworthy that the aryl fragments themselves and the ionizable groups bonded to

them in addition to the counterions are capable of redistributing electron density through $\sigma$-bonds (inductive effects) and the $\pi$-system (resonance effects). Resonance effects are highly sensitive to changes of the dihedral angle between the mean plane of the macrocycle and those of the aryl fragments. The

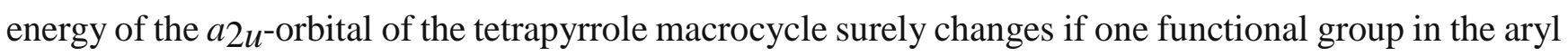
para-position is replaced by another. According to the literature [18], it correlates with the Hammett $\sigma$ constant for the given functional group. It was shown that the donor capability of the peripheral aryl substituents

changed if their ionization state was changed. This was the basis for the halochromic effects of watersoluble tetrapyrroles $[3,4,6]$. Therefore, undissociated porphyrin species with different counterions should have different Hammett $\sigma$ constants. Thus, the Hammett constants $\sigma_{n}=0.23$ and 0.18 for $\mathrm{Cl}^{-}$and $\mathrm{I}^{-}$interacting with ionized substituents in the aryl para-position. 

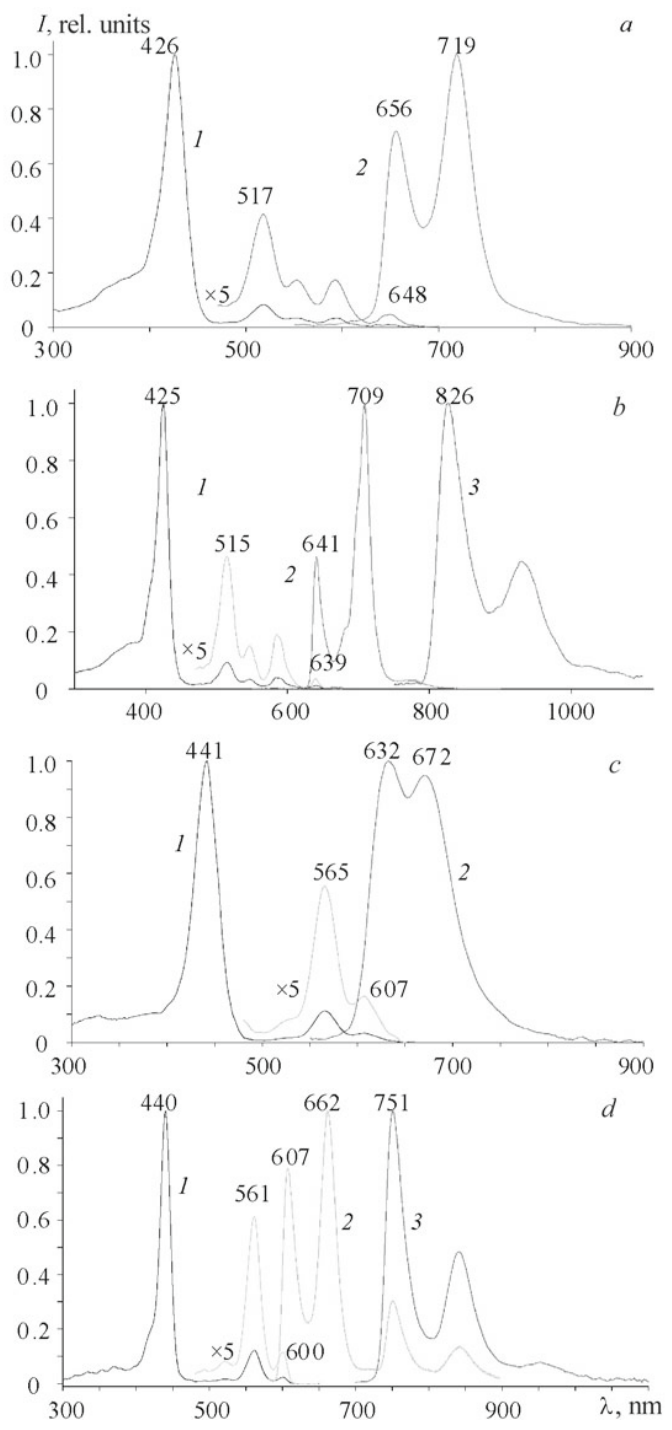

Fig. 2. Fluorescence excitation (1), fluorescence (2), and phosphorescence spectra (3) for tetraiodides of the free base (a, b) and the Zn-complex (c, d) of 5,10,15,20-tetrakis- (4- $N$-methylpyridyl)porphyrin ( $\left.\mathrm{H}_{2} \mathrm{TMPyP}\right)$ in $\mathrm{EtOH}$ at 77 (b, d) and $293 \mathrm{~K}(\mathrm{a}, \mathrm{c})$; portions of fluorescence excitation spectra in the visible range are expanded five times along the vertical for clarity; fluorescence excitation spectra of $\mathrm{H}_{2}$ TMPyP were measured with $\lambda_{\text {rec }}=$ $718 / 709 \mathrm{~nm}$; emission spectra, with $\lambda_{\mathrm{ex}}=426 / 425 \mathrm{~nm}$ (numerators and 
denominators refer to 293 and $77 \mathrm{~K}$ ); fluorescence excitation spectra of ZnTMPyP were measured with $\lambda_{\text {rec }}=675 / 751 \mathrm{~nm}$; emission spectra, with $\lambda_{\mathrm{ex}}$ $=440 / 561 \mathrm{~nm}$.

Obviously, electronic effects are more pronounced for $\mathrm{Cl}^{-}$, as opposed to heavy-atom effects. If resonance and inductive effects are examined separately, then the difference between these ions becomes even greater. The inductive and resonance Hammett constants $\sigma \mathrm{I}=0.47$ and $\sigma \mathrm{R}=-0.23$ for $\mathrm{Cl}^{-}$and 0.39 and -0.16 for $\mathrm{I}^{-}$. Therefore, it was assumed that electronic effects due to counterions in undissociated porphyrin species are important for generating the photophysical properties of the studied porphyrins at $77 \mathrm{~K}$. The fluorescence and phosphorescence quantum yields measured for porphyrins in which the macrocycle meso-positions were substituted by para- and meta-pyridyl fragments argued in favor of this hypothesis (Table 1). In all instances (for free bases and Zncomplexes), tosylate was the counterion. However, the fluorescence quantum yield $\Phi_{\mathrm{fl}}$ varied by more than two times; the phosphorescence quantum yield $\Phi_{\text {phos }}$, by almost two times. Obviously, electronic effects that differed for the para- and meta-isomers of the peripheral substituents were responsible for this.

The positions of the absorption and luminescence band maxima were also reflective of the aforementioned electronic effects. Spectral shifts were consistently observed but were less than several tens of $\mathrm{cm}^{-1}$. Table 1 shows that the energy gap between the lowest singlet and triplet states $\Delta E\left(S_{1-}\right.$ T1) was $\sim 300-350 \mathrm{~cm}^{-1}$ less for the pyridyl-substituted porphyrins than for the phenyl-substituted derivative. The differences in the position of the lowest triplet $T_{1}$-state for these porphyrins was measured experimentally for the first time and explained differences in the literature values of the intersystem-crossing quantum yield into the triplet state of $\mathrm{H}_{2}$ T4MPyP and $\mathrm{H}_{2} \mathrm{~T} 4 \mathrm{SPP}[9,12]$. The quantum yield of the former was greater than that of the latter. This agreed with the inverse dependence 
of the nonradiative transition quantum yield on the energy difference of the combining states $\Delta E\left(S_{1-}\right.$ $\left.T_{1}\right)$ [8]. It is noteworthy that absorption and luminescence spectra of ZnTMPyP at room temperature did not follow the mirror symmetry law (Fig. 2c). The intensity ratio of the electronic and vibronic transition bands in the fluorescence spectrum was greater than unity whereas the reverse relationship was observed in the absorption spectrum. The ratio $Q x(0,0) / Q x(1,0)<1$ in the absorption spectrum implied that the potential surfaces of the ground $S_{0}$ and excited $S_{1}$ states were shifted relative to each other. In our opinion, the ratio $Q x(0,0) / Q x(0,1)>1$ in the fluorescence spectrum because the porphyrins underwent conformational rearrangements during the excited-state lifetime that decreased the shift of the $S_{1}$-state potential surface relative to that of the ground $S_{0}$-state. The molecular conformations of these states were similar. Observance of the mirror-symmetry law by ZnTMPyP in the solid solution at $77 \mathrm{~K}$ argued in favor of this interpretation. The frozen solvate shell prevented the molecule from changing conformation. The intensity ratios of the electronic and vibronic transition bands in absorption and fluorescence spectra turned out to be similar.

Conclusions. It was shown that free bases and $\mathrm{Zn}$-complexes of water-soluble porphyrins at 77 $\mathrm{K}$ could undergo radiative deactivation through both fluorescence $\left(S_{1}-S_{0}\right)$ and phosphorescence channels $\left(T_{1}-S_{0}\right)$. Radiative deactivation at

$293 \mathrm{~K}$ was observed only in the $S_{1}-S_{0}$ channel. It was found that the spectral and photophysical properties of the studied compounds were changed by a combination of spin-orbit coupling (heavy-atom) and electronic effects of the counterions associated with the peripheral substituents. These effects were small so that radiative deactivation of the water-soluble porphyrins in general was slightly sensitive to the counterions of the peripheral substituents and was determined mainly by the molecular structure of the porphyrin ligand.

The photophysical and spectral properties of the studied compounds changed little. However, the results had indubitable practical value. The photophysical properties of porphyrins with different 
counterions differed little so that a counterion could be chosen to synthesize novel porphyrin photosensitizers and their carriers considering only the sensitizer with the maximum tumor-seeking properties, which were shown to depend on the type of counterion [2]. The photodynamic efficiency of the sensitizer remained practically constant.

Acknowledgments. The work was supported financially by the Belarusian Republican Foundation for Fundamental Research (Project F16RA-007), the European Union's Horizon 2020 research and innovation programme under the Marie Skłodowska-Curie grant agreement No. 645628, Convergence 2020 (Task 3.01) and Photonics and Opto- and Microelectronics (Task 1.3.01) state programs for scientific research.

\section{REFERENCES}

1. O. A. Golubchikov, O. I. Koifman, and G. V. Ponomarev, in: N. S. Enikolopyan (Ed.), Porphyrins: Spectroscopy, Electrochemistry, Applications [in Russian], Nauka, Moscow (1987), pp. 214-261.

2. A. V. Reshetnikov, V. I. Shvets, and G. V. Ponomarev, in: O. A. Golubchikov (Ed.), Progress in Porphyrin Chemistry

[in Russian], NII Khimii SPbGU, St. Petersburg (1999), pp. 70-114.

3. N. N. Kruk, O. P. Parkhots, and N. V. Ivashin, in: O. A. Golubchikov (Ed.), Progress in Porphyrin Chemistry [in Russian], Vol. 3, NII Khimii SPbGU, St. Petersburg (2001), pp. 217-232.

4. N. N. Kruk, O. P. Parkhots, and N. V. Ivashin, Zh. Prikl. Spektrosk., 68, No. 6, 709-713 (2001) [N. N. Kruk, O. P. Parkhots, and N. V. Ivashin, J. Appl. Spectrosc., 68, No. 6, 924-929 (2001)].

5. N. N. Kruk, Zh. Prikl. Spektrosk., 75, No. 2, 170-176 (2008) [N. N. Kruk, J. Appl. Spectrosc., 75, No. 2, 174-180 (2008)].

6. N. N. Kruk, in: Proc. VIth Int. Conf. "Laser Physics and Optical Technologies" [in Russian], Part 2, GrGU im. Ya. Kupaly, Grodno (2006), pp. 220-222.

7. K. Kalyanasundaram and M. Neumann-Spallart, J. Phys. Chem., 86, 5163-5169 (1982). 
8. K. Kalyanasundaram, J. Chem. Phys., 23, 2453-2459 (1984).

9. A. A. Krasnovskii, Jr., S. Yu. Egorov, O. V. Nazarova, E. I. Yartsev, and G. V. Ponomarev, Biofizika, 32, 982-993 (1987).

10. F. J. Vergeldt, R. B. M. Koehorst, A. Van Hoek, and T. Schaafsma, J. Phys. Chem., 99, 4397-4405 (1995).

11. T. Gensch, C. Viappiani, and S. Braslavsky, J. Am. Chem. Soc., 121, 10573-10582 (1999).

12. N. N. Kruk and I. N. Nichiporovich, Zh. Prikl. Spektrosk., 71, No. 3, 316-322 (2004) [N. N. Kruk and I. N. Nichiporovich, J. Appl. Spectrosc., 71, No. 3, 343-349 (2004)].

13. A. G. Tovmasyan, L. A. Sahakyan, N. S. Babayan, G. H. Gasparyan, K. S. Margaryan, G. G. Hovhannisyan, R. M. Aroutiounyan, and R. K. Ghazaryan, J. Porphyrins Phthalocyanines, 12, 1100-1110 (2008).

14. G. S. Nahor, J. Rabani, and F. Grieser, J. Phys. Chem., 85, 697-702 (1981).

15. N. N. Kruk and A. A. Korotkii, Zh. Prikl. Spektrosk., 67, No. 6, 703-707 (2000) [N. N. Kruk and A. A. Korotkii, J. Appl.

Spectrosc., 67, No. 6, 966-971 (2000)].

16. E. I. Zen'kevich, E. I. Sagun, V. N. Knyukshto, A. M. Shul'ga, A. F. Mironov, O. A. Efremova, R. Bonnet, and M. Kassem, Zh. Prikl. Spektrosk., 63, No. 4, 599-612 (1996) [E. I. Zen'kevich, E. I. Sagun, V. N. Knyukshto, A. M. Shul'ga, A. F. Mironov, O. A. Efremova, R. Bonnet, and M. Kassem, J. Appl. Spectrosc., 63, No. 4, 502-513 (1996)].

17. K. N. Solov'ev and E. A. Borisevich, Usp. Fiz. Nauk, 175, 247-270 (2005).

18. M. Meot-Ner and A. D. Adler, J. Am. Chem. Soc., 97, 5107-5111 (1975).

19. N. N. Kruk, Zh. Prikl. Spektrosk., 73, No. 5, 613-619 (2006) [N. N. Kruk, J. Appl. Spectrosc., 73, No. 5, 686693 (2006)]. 